\title{
Bone marrow and kidney fat indices in male and female (gravid and non-gravid) springbok in the Northern Cape
}

\author{
I.B. Oosthuizen ${ }^{\#}$ \\ Department of Animal, Wildlife and Grassland Sciences, University of the Free State, P.O. Box 339, Bloemfontein, \\ 9300, South Africa
}

\begin{abstract}
Kidney Fat Index (KFI) is the most used indicator of body condition for African ungulates and regarded most reliable. The possible use of Metatarsus Marrow Dry Weight (MMDW) as an alternative for KFI and femur marrow dry weight as indices of body condition for Antidorcas marsupialis (springbok) was investigated in this study. The KFI of males was lower than that of both non-gravid and gravid females. Non-gravid females had a KFI lower than that of gravid females. In non-gravid females the MMDW was lower than that of males as well as gravid females. For gravid females the MMDW was higher than that of non-gravid females. It can be reasoned that MMDW is less sensitive than KFI to variations in body condition, but it is reasonably sensitive for pregnancy. The possible use of MMDW as an indicator of body condition is important due to the unreliable availability of kidneys and kidney fat, as well as femur bones.
\end{abstract}

Keywords: Metatarsus bone marrow, fat storage, body condition.

\#Corresponding author. E-mail: oosthib.sci@mail.uovs.ac.za

\section{Introduction}

Determining body condition of game in the field accurately is not easy as it is not always possible to get close to the animals, and their colour and prevailing light might distort vision. Techniques have therefore been developed to quantify the condition of dead animals. Kidney fat index (KFI) (Riney, 1955) is probably one of the most widely used techniques, and considered to be the most reliable indicator of body condition (Riney, 1960; Batcheler \& Clarke, 1970; Caughley, 1970; Anderson et al., 1972; Mitchell et al., 1976; Atwell \& Bhika, 1984; Stelfox \& Hudson, 1986; Shackelton \& Granger, 1989; Van Rooyen, 1993; Takatsuki, 2000). A high correlation has been found between kidney fat index (KFI) and femur bone marrow dry weight (FMDW) (Gallivan \& Gulverwell, 1995; Schmidt, 1999; Takatsuki, 2000; Husseman et al., 2003).

Large numbers of game (especially Springbok, Antidorcas marsupialis) is culled annually to reduce their numbers. Hunters and game culling contractors keep the carcasses intact and often retain the kidneys and kidney fat in the carcass, which render their use for any experimental purpose impractical. Determining and utilizing KFI and FMDW as indices of body and habitat condition is thus not possible. This study therefore investigated the alternative use of the marrow fat index of the readily available metatarsus bone (MMDW) as an indication of body condition. No literature on the use of MMDW as an indicator of body condition of springbok could be found.

\section{Materials and Methods}

Samples of kidneys, kidney fat and metatarsus bones were collected from 24 springbok (6 male, 11 non-gravid and 7 gravid females) during a cull in November 2003 on the farm Suffolk in the Northern Cape Province. All the samples taken were from specimens older than 18 months (judged by horn shape and teeth). No femur bones could be collected as the landowner kept the carcasses intact. The reproductive tract of each female in the sample was examined for the presence of an embryo or foetus upon evisceration of the carcass. Both kidneys and the capsula adiposa were removed within an hour post-mortem and weighed to the nearest gram on an electrical precision balance. KFI were determined using the method of Riney (1955) where the relative average weight of the fat tissue around the kidney was expressed as percentage of kidney weight.

Both metatarsus bones of each specimen were collected and kept on ice. Within 48 hours the proximal and distal parts were removed and the central parts $(5 \mathrm{~cm}$ long) of the metatarsus used. The wet marrow was weighed, put in a crucible, then oven-dried at $80{ }^{\circ} \mathrm{C}$ for 24 hours (Neiland, 1970) and weighed again to determine the dry marrow weight. Marrow weight was taken to the nearest $0.01 \mathrm{~g}$ by electronic precision balance. The MMDW index was taken as the percentage weight of dry to wet bone marrow. 
Differences between KFI and MMDW sample means for males, non-gravid females and gravid females were determined using Tukey's LSD (least significant difference) procedure for comparison (Steel $\&$ Torrie, 1980) and separation of means $(\mathrm{P}<0.05)$.

\section{Results and Discussion}

The KFI of males was lower $(\mathrm{P}<0.05)$ than that of both non-gravid and gravid females (Table 1$)$. The poorer condition could be associated with the high activity (between recently introduced Kalahari rams and other bachelor rams) observed at the time of the cull, as well as the absence of rain up to the time of the cull. Dunham \& Murry (1982) as well as Schmidt (1999) found the same trend for impala as for blesbok $\mathrm{x}$ bontebok hybrids.

The KFI of non-gravid females was also lower $(\mathrm{P}<0.05)$ than that of gravid females (Table 1$)$. According to Van Rooyen (1993), a possible explanation for this is that ruminants store energy in the form of fat during the first two trimesters of pregnancy (due to higher oestrogen levels). This stored energy is then used during the third trimester and in early lactation when the demands of the foetus or lamb result in lipid mobilization.

The MMDW of non-gravid females was lower $(\mathrm{P}<0.05)$ than that of males and gravid females. The MMDW of gravid females was higher $(\mathrm{P}<0.05)$ than that of non-gravid females. Though most authors have used femur fat, metatarsus fat (like metacarpus fat; Gallivan \& Gulverwell, 1995) appears to decline more slowly than femur marrow fat, suggesting it is used at a later stage of fat depletion (Chan-McLeod et al., 1995; Takatsuki, 2000). Thus, the marrow dry weight of the metatarsus is more sensitive for animals in poor condition, but may be less sensitive for those in fair condition.

Table 1 Kidney fat index (KFI) and metatarsus marrow dry weight index (MMDW) values (mean \pm s.e.) of springbok (Antidorcas marsupialis) for males $(n=6)$ or non-gravid $(n=11)$ and gravid females $(n=7)$ in the Northern Cape

\begin{tabular}{lcc}
\hline Classification & KFI (\%) & MMDW (\%) \\
\hline Males & $10.28^{\mathrm{a}} \pm 0.86$ & $84.43^{\mathrm{a}} \pm 0.96$ \\
Non-gravid females & $61.07^{\mathrm{b}} \pm 1.34$ & $81.65^{\mathrm{b}} \pm 0.65$ \\
Gravid females & $67.17^{\mathrm{c}} \pm 2.89$ & $91.77^{\mathrm{c}} \pm 0.35$ \\
\hline
\end{tabular}

Mann-Whitney U-test: Different letters (a, b and c) between the mean Kidney Fat Index (KFI) and Metatarsus Marrow Dry Weight Index (MMDW) of each animal group indicates a significant difference $(\mathrm{P}<0.05)$.

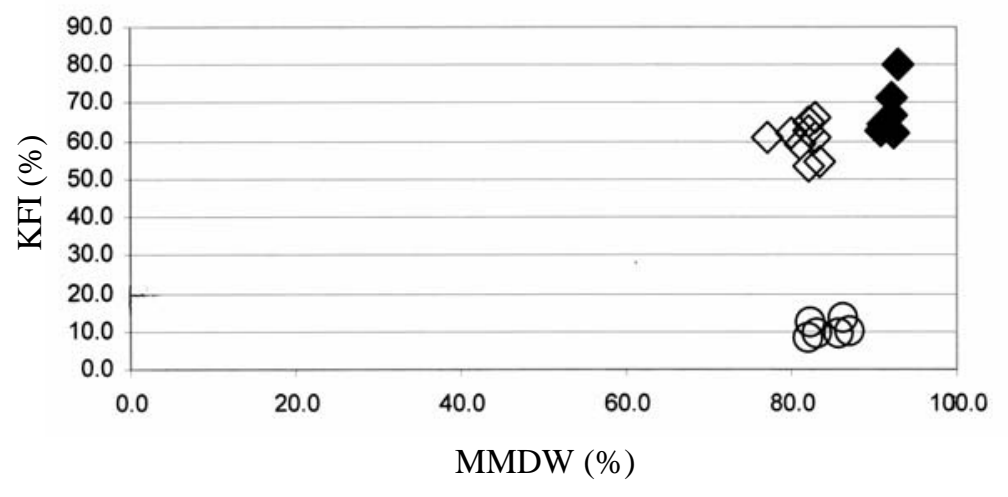

Figure 1 Kidney Fat Index (KFI (\%)) and Metatarsus Marrow Dry Weight Index (MMDW (\%)) of Antidorcas marsupialis (springbok) for males $(\mathrm{O})$ and non-gravid $(\diamond)$ or gravid females $(\diamond)$ in the Northern Cape

The relationship between the KFI and MMDW in this study formed clusters (Figure 1), with only the values for the specimen in very poor condition completely separated. The clustering of KFI and MMDW values for males, non-gravid and gravid females indicate that the specimens within each group were of very similar condition at the time of sampling. 


\section{Conclusions}

The use of MMDW as an indicator of body condition has not yet been studied thoroughly. This study shows that MMDW may have a useful application as a parameter of body condition, or of the effect of pregnancy on the body condition. The low number of springbok available at the time of the study may mask the value of MMDW in relation to KFI as an indicator of body condition, and needs further study with a larger number of specimens. Further sampling should also be done at regular intervals through out the year, as variation in body condition at different times of the year could induce a different spatial distribution of KFI and MMDW values among and within groups. The correlation of KFI and MMDW with carcass condition scores should also be investigated. MMDW can be very important as an indicator of body condition, due to the unreliable availability of kidneys and kidney fat, as well as femur bones.

\section{References}

Anderson, A.E., Medin, D.E. \& Bowden, D.C., 1972. Indices of carcass fat in a Colorado mule deer population. J. Wildl. Man. 36, 579-594.

Atwell, C.A.M. \& Bhika, M., 1984. Feeding ecology of impala on Starvation Island, Lake Kariba. S. Afr. J. Wildl. Res. 15, 41-48.

Batcheler, C.L. \& Clarke, C.M.H., 1970. Note of kidney weights and kidney fat index. N. Z. J. Sci. 13, 663668.

Caughley, G., 1970. Eruption of ungulate populations, with emphasis on Himalayan thar in New Zealand. Ecol. 51, 53-72.

Chan-McLeod, A.C., White, R.G. \& Russel, D.E., 1995. Body mass and composition indices for female barren-ground caribou. J. Wildl. Man. 59, 278-291.

Dunham, K.M. \& Murry, M.G., 1982. The fat reserves of impala Aepyceros melampus. Afr. J. Ecol. 20, 8187.

Gallivan, G.J. \& Culverwell, J., 1995. Body condition indices of impala Aepyceros melampus: Effect of age class, sex, season and management. S. Afr. J. Wildl. Res. 25, 23-31.

Husseman, J.S., Murry, D.L., Power, G. \& Mack, C.M., 2003. Correlation patterns of marrow fat in Rocky Mountain elk bones. J. Wildl. Man. 67, 742-746.

Mitchell, B., McCowan, D. \& Nicholson, I.A., 1976. Annual cycles of body weight and composition in Scottish Red deer, Cervus elephas. J. Zool. 180, 107-127.

Neiland, K.A., 1970. Weight of dried marrow as indicator of fat in caribou femurs. J. Wildl. Man. 34, 904907.

Riney, T., 1955. Evaluating condition of free-ranging red deer (Cervus elephas), with special reference to New Zealand. N. Z. J. Sci. Tech. 36, 429-463.

Riney, T., 1960. A field technique for assessing physical condition in some ungulates. J. Wildl. Man. 24, $92-$ 94.

Schmidt, A.G., 1999. Body condition in blesbok x bontebok hybrids in the Oviston Nature Reserve, Eastern Cape Province. S. Afr. J. Wildl. Res. 29, 145-147.

Shackelton, C.M. \& Granger, J.E., 1989. Bone marrow index and kidney fat index of several antelope species from Transkei. S. Afr. J. Wildl. Res. 19, 129-134.

Steel, R.G. \& Torrie, J.H., 1980. Principles and Procedures of Statistics, $2^{\text {nd }}$ Edition. New York: McGrawHill.

Stelfox, J.B. \& Hudson, R.J., 1986. Body condition of male Thompson's and Grant's gazelles in relation to season and resource. Afr. J. Ecol. 24, 111-120.

Takatsuki, S., 2000. Kidney fat and marrow fat indices of the sika deer population at Mount Goyo, northern Japan. Ecol. Res. 15, 453-457.

Van Rooyen, A.F., 1993. Variation in body condition of impala and nyala in relation to social status and reproduction. S. Afr. J. Wildl. Res. 23, 36-38. 